\title{
D. MARELO MIRAVETE DE MASERES Y SUS PROYECTOS DE PREVENCIÓN MÉDICO-SANITARIA EN LA ORIHUELA DEL SIGLO XVIII (*)
}

\author{
Por Mario MARTÍNEZ GOMIS
}

Universidad de Alicante

\section{INTRODUCCIÓN}

La figura del P. Benito Feijoo, de un tiempo a esta parte, ha comenzado a ser restituida a su verdadera dimensión de divulgador científico, abandonando de esta manera el excesivo protagonismo que se le había atribuido como impulsor e introductor de la ciencia empírica en España y como adelantado de la lucha contra la escolástica degenerada que imperaba en casi todas las ramas de nuestro saber. La razón de este cambio de pedestal - que no de condición meritoria, como muchos han querido ver - se ha debido a toda una serie de trabajos que encabezados por Ramón Ceñal, Olga Quiroz, Vicente Peset, J. M. López Piñero, S. García Martínez y Antonio Mestre ${ }^{(1)}$, entre otros, vinieron a poner de manifiesto la existencia de una generación de pensadores y hombres de ciencia que, ya durante las últimas décadas del siglo XVII, se había planteado, con tanto o más rigor que el monje benedictino, la tarea de sacar a España de su atraso: los novatores, los defensores de la historia crítica, los continuadores de un humanismo cristiano encaminado a reformar la religión y las costumbres. Una generación que, conectada con el grupo valenciano que giró en torno a la figura de Gregorio Mayans, tejió una importante red de relaciones a lo largo y ancho de la centuria siguiente, dando lugar a un grupo de ilustrados que acabaría influyendo en las decisiones que el poder monárquico comenzaba a tomar con el fin de reformar el país.

El «grupo» frente a la «individualidad», el sector «intelectual» frente al sector «político» -o si se prefiere la Ilustración frente al Despotismo- no como elementos necesariamente antagónicos, sino complementarios, y tal vez en relación causa-efecto, ha sido una de las aportaciones más interesantes a la hora de 
explicar muchos de los cambios operados en el campo de la ciencia y la cultura durante el Setecientos.

Pero los avances historiográficos no se han reducido sólo a este aspecto. La misma vinculación de nuestros ilustrados a los novatores de últimos del XVII, a una coyuntura socioeconómica y política distinta, ha puesto de manifiesto muchos de los rasgos peculiares y originales que iban a caracterizar a las Luces españolas, así como las diferentes etapas que en su evolución se observan: el eclecticismo inicial, la necesidad en algunos aspectos de aunar tradición y novedad, la influencia minoritaria del materialismo preconizado por los Philosophes, el papel jugado por la Iglesia en las reformas al identificarse con los presupuestos del llamado jansenismo histórico, etc. Toda una serie de factores, en resumen, que evidencian la complejidad del movimiento ilustrado español y que ponen al descubierto la verdadera consistencia de ese trend que hundiendo sus raíces en el Renacimiento llegaría hasta los albores del mundo contemporáneo con sus avances y retrocesos coyunturales, pero también con sus profundas diferencias de matices en el tiempo, el espacio y los contenidos.

Las Luces españolas, por lo tanto, labor de conjunto, movimiento heterogéneo en pugna contra el oscurantismo y a favor del racionalismo y del empirismo, de la renovación de las costumbres y la economía, parece haber dado un notable paso hacia adelante en cuanto a sus orígenes, componentes y protagonistas se refiere. Sin embargo, muchos aspectos quedan todavía por desbrozar, algunos de ellos no de poca importancia. Entre estos, creemos, se encuentra el problema que plantea la divulgación de las nuevas ideas.

La Ilustración española no deja de ser, hasta el momento, la obra de una élite ${ }^{(3)}$; es decir, de ciertos sectores minoritarios privilegiados por su status económico o profesional, que le permitía la adquisición de un nivel cultural elevado y el tiempo libre suficiente para dedicarse a la especulación proponiendo, de esta manera, soluciones a nivel teórico-práctico a los problemas que tenía planteados el país. Sectores en activa comunicación oral o epistolar que plasmaban sus programas de reforma a una altura que requería no sólo un cierto grado de conocimientos sino también una cierta afinidad profesional (médicos, juristas, eclesiásticos con estudios superiores, etc.) Sectores, por lo tanto, restringidos, productores de ideas, o muy próximos a los círculos donde éstas se elaboraban.

Si en todo proceso cultural, como señaló en su momento G. Dorfles ${ }^{(4)}$, es imprescindible este elemento creador que se identifica con las élites, sabemos, también, que éste no es el único que interviene en el proceso de comunicación; que existen asimismo los agentes difusores del nuevo mensaje elaborado en lo alto de la pirámide socio-cultural; agentes intermedios que propagan ese mensaje y que, en cierta medida, lo degradan o apartan de su prístina pureza, bien por el deseo de hacerlo comprensible a los estratos inferiores de la sociedad, bien como consecuencia de una personal interpretación del mismo. En el caso de la Ilustración española, el escalón correspondiente a ese nivel divulgador - no hablemos de los receptores últimos del mensaje- sigue siendo, en gran medida, una incógnita. 
Sabemos de la existencia de eruditos o ilustrados locales ${ }^{(5)}$, preocupados por las nuevas ideas, interesados en su difusión; tenemos noticias acerca de los medios de comunicación disponibles —básicamente la obra impresa-Gacetas, Diarios provinciales o regionales, opúsculos, etc., para hacer llegar a una masa desconocida de lectores las novedades aparecidas en los medios de difusión de nivel y alcance más restringido o especializado ${ }^{(6)}$. Pero el conocimiento de estos hechos no ha dado todavía paso a la sistematización, a la obra de conjunto que intente valorar las posibilidades más amplias de aceptación de esas nuevas ideas, o la calidad de las mismas con arreglo a su modelo originario, en el último tramo de su trayectoria en busca de un receptor no excesivamente cultivado.

Se trata de un problema harto complejo que vuelve a poner sobre el tapete la importancia del P. Feijoo, de su talento y carisma de cara a un sector determinado de lectores, capaz de aceptar en su obra - y sólo a través de ella, debido también, a su condición de religioso bienavenido con el régimen - lo que se negaba a aceptar en otros escritores más preparados, de lenguaje más técnico, pero que podían resultar también más sospechosos de heterodoxia o radicalismo. Un problema que no se reduce, por supuesto, al P. Feijoo, sino a los muchos Feijoo de distinta categoría que hubo en el país, y que prepararon, con mayor o menor acierto, a veces incluso con errores teóricos de bulto, el ambiente propicio para una feliz acogida, más generalizada, de las reformas y los cambios. Es la cuestión que podríamos llamar de los «ilustrados de tercer nivel» ${ }^{(7)}$; de los hombres que divulgaron inspirándose no en las fuentes directas donde se manifestaban los adelantos, sino en aquellos tratados, círculos o academias, que ya habían iniciado las tareas encaminadas a hacer asimilables las novedades; de los hombres que se dedicaron a cultivar un tipo de literatura miscelánea y bienintencionada que algunos autores han definido con el nombre de «ciencia recreativa». No cabe duda que muchos de los escritores así considerados contribuyeron a modificar los estados de opinión con respecto a los avances científicos que se estaban produciendo más allá de nuestras fronteras. El ejemplo apuntado por J. Nadal acerca de la polémica desatada, en todo tipo de escritos, sobre la inoculación, es elocuente al respecto ${ }^{(8)}$; sirvió para preparar el camino de la vacuna y lograr una mayor aceptación de su práctica; una práctica que, muchas veces, no hacía imprescindible el conocimiento de un médico llamado Jenner habitante del condado de Gloucester en la lejana Inglaterra.

El presente artículo tiene como objeto el análisis de dos pequeñas obras impresas debidas a la pluma de uno de esos ilustrados que hemos considerado como pertenecientes al «tercer nivel»: el Dr. y Canónigo oriolano D. Marcelo Miravete de Maseres. Somos conscientes de que tal vez resulte un atrevimiento atribuirle esa condición de ilustrado dadas las contradicciones que encierra su pensamiento y el mismo proyecto de prevención médico-sanitaria que intentó llevar a cabo en su Orihuela natal. Será un atrevimiento de mayor envergadura para aquellos que no acepten la complejidad del fenómeno español de las Luces, la originalidad ya aludida y el carácter prioritariamente filantrópico y utilitarista que impregnó mu- 
chos de sus proyectos y realizaciones, aún a riesgo de olvidar los principios teóricos que los originaron.

\section{MARCELO MIRAVETE DE MASERES: LA PERSONALIDAD VACILANTE DE UN ERUDITO PROVINCIANO ENTRE}

\section{LA TRADICIÓN Y LAS LUCES}

La biografía de D. Marcelo Miravete de Maseres, es la típica biografía del español de mediados del siglo XVIII que, procedente de una familia acomodada de una ciudad de provincias, abrazó el estado eclesiástico y alternó su vocación con el ejercicio de las letras. Sólo su eclecticismo en materia filosófica, su preocupación por la reforma de la Iglesia y su deseo de aumentar el nivel cultural y sanitario de sus conciudadanos, colocan al personaje fuera de esa tipología conocida del clérigo bien situado, conformista y reaccionario, que tantos obstáculos puso al desarrollo de las Luces desde la plataforma del púlpito o desde las columnas de la letra impresa.

Nacido en $1729^{(9)}$ en la capital del Bajo Segura D. Marcelo Miravete presenta un «curriculum» académico y profesional bastante común entre los hombres de su clase y vocación. Tras cursar en su niñez y adolescencia estudios de Gramática, se vio favorecido por una beca del obispo Gómez de Terán que le permitió acceder a enseñanzas superiores en el Seminario de Orihuela recién fundado por aquel prelado ${ }^{(10)}$. En este centro cursó estudios de Filosofía y Teología que incorporó más tarde a la Universidad oriolana que regían los dominicos. En ella acabó graduándose de Maestro en Artes, de Doctor en Teología y Derecho Canónico, dando comienzo así a una larga carrera de oposiciones que vio su final en 1763 al obtener la canongía lectoral de la catedral de Orihuela ${ }^{(11)}$. Atrás quedaron años de formación y peregrinaje durante los cuales el desempeño de algunas regencias de cátedra, tanto en el Seminario como en la Universidad ${ }^{(12)}$, y el disfrute de capellanías y curatos, le habían alejado momentáneamente de su patria chica, de donde, que sepamos, no se movería ya tras su ingreso en el cabildo catedralicio.

Instalado en Orihuela hasta su muerte en 1792, D. Marcelo alternó sus tareas en la Iglesia con las propias de la cátedra de Filosofía Tomista en la Universidad, alcanzando una serie de honores en el ámbito ciudadano que le llevaron al desempeño del cargo de Rector en el Estudio General durante el curso 1775$1776^{(14)}$ y al gozo de una prestigiosa fama como predicador que él mismo tuvo a bien airear en alguna de sus publicaciones, llegándose a atribuir la paternidad sobre más de seiscientas piezas oratorias salidas de su pluma ${ }^{(15)}$. Pocas cosas más conocemos acerca de la vida de este personaje. Tan sólo que llegó a disfrutar de una situación económica desahogada que le permitió dedicarse a los proyectos filantrópicos que más adelante trataremos; que fue miembro numerario de la Sociedad Económica de Amigos del País de Valencia ${ }^{(16)}$; socio de erudición y mérito de la Academia Médica-Gaditana y que mantuvo contactos epistolares, entre 
1771 y 1774 , con D. Gregorio Mayans y Síscar ${ }^{(17)}$. Justo Pastor Fuster, al incluir a D. Marcelo en la Biblioteca Valenciana ${ }^{(18)}$, aporta algunos datos más sobre sus escritos. En primer lugar, tras corroborar sus dotes de orador, menciona la publicación de las dos obras objeto de nuestra comunicación; Justa de Piedad y Compasión, para socorro de los ahogados, y de los que caen con aparente muerte repentina ${ }^{(19)}$, y El Espudeo, o el hombre Industrioso y Estudioso. Sueños Morales de instrucción física muy notable en beneficio de todos quantos aparecen muertos sin estarlo: e ilustración al Papel de la Junta de Piedad que ha publicado el $D r . .{ }^{(20)}$. Añade asimismo la existencia de un trabajo manuscrito Paráfrasis de los Salmos Penitenciales ${ }^{(21)}$, pero deja en el tintero algunos opúsculos impresos que muy bien pudieron ser muestra de una producción literaria más amplia del canónigo como escritor sagrado ${ }^{(22)}$.

Vivió D. Marcelo a partir de 1763 una época interesante en el marco de su Orihuela natal. Al menos en lo que hace referencia a los aspectos de la vida cultural y académica que giraba en torno al Seminario de San Miguel y a la Universidad. Es cierto que los años de disputas y violencias entre los colegiales y canónigos en pos del control del Seminario se habían atenuado ${ }^{(23)}$, que aquellos tiempos turbulentos de su época de estudiante habian pasado. Pero no así las tensiones. Seminario y Universidad polarizaron durante el período 1760-1770 un sordo enfrentamiento que se hizo patente en la diferencia de sus planes de estudios: el implantado por Gómez de Terán, prelado de ideas pro-jesuíticas, que imperaba en San Miguel, y aquel otro, más obsoleto, que regía en el viejo Estudio General controlado por los dominicos. Tensiones que pasaron a un segundo plano al iniciarse la década siguiente y plantearse el gobierno la extinción de las Universidades Menores - entre las que se encontraba la de Orihuela- y al ordenar la expulsión de la Compañía de Jesús prohibiéndose con ello las enseñanzas propias de su escuela y quedando, por tanto, el Seminario en delicada situación.

D. Marcelo fue testigo y parte interesada tanto de estos acontecimientos como de sus consecuencias más inmediatas. Vivió los años clave en que el reformismo de Carlos III obligó al Claustro de la Universidad oriolana a reformar su Plan de Estudios y a clausurar su Facultad de Medicina con las consiguientes protestas por parte de la ciudad ${ }^{(24)}$. Tras este hecho, ocurrido en 1783 , asistió asimismo a la reforma de los estudios con el apoyo incondicional del Consejo de Castilla. Tiempos nuevos en los que las enseñanzas filojansenistas, el rigorismo moral, la introducción de la historia crítica, el nuevo impulso al estudio de las lenguas griega y hebrea - como materia indispensable para un mejor conocimiento de las Sagradas Escrituras-, hacían irrupción en Orihuela con la intención de formar un clero más preparado y de ofrecer otra alternativa más avanzada al etudiantado laico de la comarca, que no fuera la que presentaba la timorata reforma universitaria lastrada, a nivel local, por los dominicos ${ }^{(25)}$.

No abundan, sin embargo, los datos que evidencien la postura de nuestro personaje ante coyuntura tan delicada. Parte interesada de las tres instituciones -Cabildo, Universidad y Seminario «...Jamás me pongo otro título apenas, que 
el de Seminarista», decía D. Marcelo en $1791^{(26)}$ - parece ser que el canónigo oriolano optó por una posición de difícil equilibrio que no le impidió acercarse con timidez a las ideas ilustradas. El ambiente cultural de Orihuela, conservador a pesar del esfuerzo de algunos obispos que llegados de fuera intentaban comenzar las reformas, no sería muy propicio para intentar la aventura ilustrada sin ver por ello amenazada la tranquilidad de su existencia e, incluso, su privilegiada posición social y económica. No está de más aquí recordar el antagonismo crónico existente entre el Cabildo catedralicio y los prelados ${ }^{(27)}$, los problemas que enfrentaron a los canónigos con la Universidad y la dependencia de esta institución con el Colegio de Predicadores, una de las fuerzas económicas más importantes de la capital del Bajo Segura durante buena parte de los siglos XVII y XVIII ${ }^{(28)}$.

A pesar de estos inconvenientes, D. Marcelo, con cautela, se aproximó a las fuentes que trataban de impulsar las reformas. Buena prueba de ello la tenemos en el contacto epistolar mantenido con D. Gregorio Mayans. A través de esta correspondencia sabemos de la admiración que sentía el oriolano por el erudito de Oliva y de cómo un mero contacto comercial - la compra por parte de la Universidad de la Gramática latina mayansiana, gestionada por D. Marcelo- se convirtió en una larga amistad en la que no faltaron los consejos y las recomendaciones en materia cultural a que tan dado fue el valenciano. Una muestra palpable de ello, es la solicitud por parte del Canónigo de varios ejemplares del impreso que Mayans publicó sobre Witiza ${ }^{(29)}$ y del interés mostrado por D. Marcelo, a partir de la recepción del envío, por otros aspectos de la historia crítica. De igual manera, en el campo de la oratoria sagrada, D. Marcelo se confesó ferviente admirador de El orador cristiano ${ }^{(30)}$ aunque, como veremos más adelante, a nivel personal consideraba improbable el llevar muchos de sus contenidos a la práctica.

Otros datos nos hablan de D. Marcelo como un espíritu curioso y nada hostil a las reformas. En el campo de la filosofía habló respetuosamente de Descartes calificándole de «insigne filósofo» ${ }^{(31)}$. Del mismo modo, en lo que hace referencia a los estudios filológicos se consideró ferviente admirador del Deán de Alicante D. Manuel Martí, cuyos escritos no dudó en recomendar, en una de sus obras, para una perfecta instrucción en la lengua latina ${ }^{(32)}$. Enemigo de la incultura y la superstición, de los clérigos de «misa y olla», se decantó hacia un reformismo de la religiosidad basado en el abandono de ciertas prácticas externas y en la búsqueda de una caridad eficaz y poco ostentosa, llegando a decir, sobre este particular, que aquellos que se vanagloriaban de otorgar cuantiosas e indiscriminadas limosnas a los pobres no sólo eran los causantes del aumento de la mendicidad sino aquellos que «...en medio de sus tonterías, cogerían el Cielo, en verdad a título de insuficiencia... ${ }^{(33)}$. Lector de Fleury ${ }^{(34)}$, por resumir, y entusiasta de Feijoo ${ }^{(35)}$, D. Marcelo, no obstante estas inclinaciones en que se conjugan novedad y tradición en aras de un cambio en la ciencia y las costumbres, fue, creemos, no un espíritu plenamente convencido de todo cuanto suponían las $\mathrm{Lu}$ ces, sino un espíritu inquieto y curioso. Un hombre atrapado en una ciudad de provincias en la encrucijada de unos tiempos que cambiaban quizá demasiado de- 
prisa para desarraigar por completo aquellos elementos característicos de una educación menos avanzada. Sólo de este modo se explican muchas de las contradicciones que presentan las notas que hemos podido extraer sobre su vida y sus ideas.

Si está claro el desdén de D. Marcelo hacia Voltaire y el materialismo ${ }^{(36)}-$ pocos fueron los clérigos españoles capaces de admirar al filósofo francés-, si resultan lógicos, también, sus errores y la creencia en prácticas supersticiosas en materia de medicina, debido a un exceso de voluntarismo y ansias de erradicación de determinados accidentes y enfermedades, son menos explicables otros deslices en abierta oposición con cuanto parecía defender en su terreno más específico de la religión y las humanidades. Es por esto que resulte curiosa su creencia en determinados milagros como la aparición de las almas ${ }^{(37)}$, o que nos choque su defensa acerca de la creación de cofradías piadosas en contra del sentir generalizado de los obispos ilustrados ${ }^{(38)}$, o que, a pesar de sus elogios al Orador cristiano, llegase a escribir, años más tarde, una frase elocuente que nos habla de las dificultades de desprenderse del lastre del pasado: «En quanto al predicar, entonces eran de moda aquellas sutilezas, y no nos cuidabamos mucho de imitar a Cicerón, como ahora se cuida, no sé si con mayor fruto...) ${ }^{(39)}$

Tal vez parte del moderantismo de $\mathrm{D}$. Marcelo se daba a un incidente ocurrido entre 1770-1772 y que dio pie a buena parte de la correspondencia cruzada entre el Canónigo y Mayans. Nos referimos al enfrentamiento que D. Marcelo sostuvo durante este periodo con Juan Bautista Hermán. El problema surgió a raíz de un voto hecho por el oriolano al obispo Pedro Albornoz de publicar ciertas vespertinas si ganaba la oposición a la canongía lectoral de Orihuela ${ }^{(40)}$. Dichas vespertinas fueron compuestas, según su autor, en base a la glosa de El libro de los Cantares, a las que añadió una serie de sermones inspirados en el mismo texto . J. B. Hermán, censor del manuscrito, envió un informe desfavorable sobre el mismo al Consejo de Castilla fundándose no en base a la fuente de inspiración, poco sospechosa de conservadurismo, sino, por el contrario, en razón de la falta de notas o referencias críticas que debían incluirse para su publicación con el fin de que el texto "...no pareciese obra fraylesca» (41). Esta correcta justificación del censor para impedir la publicación de las vespertinas, no debió ser la única que impulsó a J. B. Hermán a dar su voto negativo. Esto se desprende de los continuos intentos de D. Marcelo por recuperar su original para corregirlo, de su requerimiento a Mayans - amigo de Hermán - para que intercediese a su favor y del caso omiso que hizo el censor a tales solicitudes dando largos al asunto y reteniendo la composición del Canónigo. D. Marcelo, que deseaba evitar todo escándalo en el que pudiese verse involucrado su nombre, se deshizo ante Hermán en todo tipo de inútiles justificaciones. Sobre el proceso de redacción de su texto indicaba a su intercesor Mayans que en aquel momento «...hallábame sin libros i aiudado de mi aplicación logré glosar el Psalmo 50...» ${ }^{(42)}$ Esgrimía a continuación que, a pesar de ello, lo había compuesto «...con estilo limpio, pero pastoral i acomodado al gusto del Pueblo... ${ }^{(43)}$, con la clara intención de lograr a través de «...la mediación de aquella Sr. ${ }^{a}$ (la virgen) la reforma de las costum- 
bres...» (44) Añadía que estaba seguro de no haber incurrido en el «cáncer de la mala doctrina» ${ }^{(4)}$ ya que su forma de «...opinar, de hablar y de predicar era una misma y lo había sido siempre» ${ }^{(46)}$, recibiendo por ello grandes elogios de los claustros de las Universidades de Cevera y Solsona, e incluso en «...el sabio seminario de San Vicente de Paul de Barcelona i aun siendo alli obispo el señor Sales») ${ }^{(47)}$ quien había hecho grandes elogios de su verbo y doctrina.

De todas estas cuestiones parece desprenderse un desproporcionado temor por parte de $\mathrm{D}$. Marcelo que llegó incluso a pedir a su censor, con tal de recibir el manuscrito, que le detallase uno por uno los errores posibles para rectificarlos, concluyendo con evidente humildad mediante un «...¿no sería lástima dexar sin luz a un ciego que la busca, para hallar la verdad en su recto camino?...) (48)

Temiese alguna represalia del tipo que fuese o no por su escrito, el caso es que el Canónigo oriolano no pudo olvidar jamás este incidente cuya resolución final desconocemos. En 1791, a punto de dejar ya este mundo, aludía todavía con amargura a ciertos ataques recibidos en Madrid ${ }^{(49)}$. Es probable, por lo tanto, que el conflicto contribuyese a su moderación y a esa actitud dubitativa o contradictoria que evidencian sus escritos. Pero no creemos que esto importe demasiado a la hora de valorar determinadas realizaciones llevadas a cabo por nuestro personaje. En 1791 cuando intentaba implantar su Junta de Piedad y generalizar el uso de la Máquina Fumigatoria, colaboraba en El Correo de Murcia proponiendo a los lectores cuestiones para que se ejercitasen en la crítica histórica, otorgando como premio - con mucha autoestima, dicho sea de paso- algunos de los folletos salidos de su pluma ${ }^{(50)}$.

Sobre D. Marcelo parece pesar una verdad y una característica del siglo XVIII tener en cuenta, y es aquella apuntada por E. H. Ackerknecht y compartida por E. Cassirer y J. A. Maravall acerca de que la Ilustración no estuvo «orientada hacia objetivos trascendentales, sino en y para este mundo» ${ }^{(51)}$, que la Ilustración fue, más que una filosofía, «el uso que se hizo de ella» ${ }^{\left({ }^{(2)}\right)}$ Y D. Marcelo usó de algunos de sus principios entendiese o no la causa última que los originaba. En especial usó de aquellos que no repugnaban excesivamente los fundamentos de su educación y que venían respaldados por un cierto criterio de autoridad. Principios cuya aplicación práctica, por otra parte, aparecían como factibles a la hora de proporcionar efectos benefactores para sus semejantes. De algunas de estas ideas relacionadas con la prevención médico-sanitaria trataremos en las páginas que sigue.

\section{LA CULTURA MÉDICA DE UN CANÓNIGO Y SU PREOCUPACIÓN EN TORNO AL TEMA DE LA «MUERTE APARENTE»}

D. Marcelo Miravete de Maseres no fue un hombre dedicado en exclusividad a las actividades relacionadas con el estudio o la práctica de la Medicina. A pesar de su vinculación con la Academia Médico Gaditana, de su amistad con los gale- 
nos oriolanos que habían formado parte de la extinta Facultad universitaria de su localidad, el Canónigo confesaba los fundamentos de su limitada cultura en este campo del saber:

«Yo, a la verdad no soy Médico, ni cosa que le parezca, ni he estudiado la Cirujía, y a lo más se quatro cosas de estas facultades, especialmente de la primera, porque leo a Solano de Luque, y la Medicina Hipocrática del Doctor D. Francisco Rubio, Médico de Familia de S. M. C. y he leido quanto dice Feijó sobre su práctica, y no sé que otras noticias, pero esto no basta para hablar con satisfacción en estas materias.... ${ }^{(53)}$

Sus conocimientos sobre esta ciencia, tan sólo de carácter interdisciplinar, fueron fruto de una serie de lecturas, de espíritu meramente divulgador, que le llevaron a interesarse por una serie de temas que estaban sensibilizando a la opinión pública española y que no tardó en compartir.

Nos referimos a aquellos aspectos de la prevención médico-sanitaria que tuvieron como objeto la lucha contra la «muerte aparente», los «insultos apopléticos» y contra toda una serie de accidentes, muy propios de la época, producidos por ahogos en los ríos y canales y por las asfixias ocasionadas a raíz de las emanaciones de braseros, letrinas, enterramientos, etc. La preocupación por erradicar estos males era ya un hecho abordado en Europa desde mediados del siglo XVIII y se inscribe plenamente en esa actitud asumida por los estados absolutistas tendente a convertir este tipo de problemas en objeto de administración y legislación ${ }^{(54)}$. Actitud que sirvió para aglutinar a profesionales de la Medicina junto a otros elementos profanos en la propaganda de las nuevas medidas sanitarias con el fin de evitar los males señalados y otras enfermedades hasta el momento desatendidas: el alcoholismo, la demencia, los accidentes laborales, etc.

Una abundante literatura sobre el tema de la reanimación de ahogados y la lucha contra la «muerte aparente» circulaba ya desde mediados de siglo al otro lado de los Pirineos. El tratado de Winslow (1740) y el de Bruhier (1752), son un ejemplo sobre el particular. El propio Johan Peter Frank, considerado como uno de los impulsores de la política médica se había interesado asimismo en la materia ${ }^{(56)}$ al igual que Van Swieten en el marco de la Viena ilustrada de María Teresa ${ }^{(57)}$. El médico Patak en Alemania participaba de idénticas ideas ${ }^{(58)}$ y lo mismo ocurría con Auguste Tissot, el traductor de Haller al francés, y con John Hunter en Inglaterra, quien, al parecer, había llegado a construir un aparato para la práctica de la respiración artificial ${ }^{(59)}$.

Pero no fueron éstas las fuentes directas en cuyas aguas bebiera D. Marcelo el contagio de la inquietud. Reconocía su deuda con los contenidos del Teatro Crítico de Feijóo - más que con Solano o el Setabense- ${ }^{(60)}$, pero el resto de su formación galénica se debía a la lectura de la prensa madrileña. A través de los artículos de la Gaceta de Madrid, del Diario Enciclopédico, de El espiritu de los mejores diarios, etc. ${ }^{(61)}$, D. Marcelo confiesa en ocasiones el conocimiento que tuvo de aquellos autores - Sage, Gardan, Janin, Taringet, el propio Tissot ${ }^{(62)}-$ y de toda una serie de teorías y prácticas terapéuticas que le servirían para respal- 
dar con firmeza - según creía él- los proyectos preventivo-sanitarios que intentó implantar en Orihuela.

El resultado de esta serie de lecturas misceláneas y recreativas fue la configuración de un endeble bagaje cultural en materia médica que se manifiesta a menudo en los dos escritos que el Canónigo dedicó a estos problemas: la Junta de Piedad... y El Espudeo... Ambas obras reflejan la falta de sentido crítico que preside la selección de información, su excesiva confianza en la misma y un ingenuo afán voluntarista que no conoce desmayo. Sus páginas suelen acumular todo tipo de remedios, por muy disparatados que sean, contra las enfermedades y accidentes que pretende combatir, logrando en ocasiones desacreditar - o cuanto menos poner en duda - la eficacia de su proyecto fundamental: el empleo de la Máquina Fumigatoria y del Alkalí volátil para restituir a la vida a los ahogados y axfíticos. Así, por ejemplo, al lado de atrevimientos que suelen responder a presupuestos más o menos novedosos - la posibilidad de reanimar a los apopléticos mediante el uso de corrientes eléctricas ${ }^{(63)}$, el empleo del termómetro para medir la temperatura del cuerpo humano ${ }^{(64)}$, la creación de cementerios públicos en las áreas periféricas de las ciudades que evitasen los peligros de los enterramientos en iglesias ${ }^{\left({ }^{65}\right)}$, etc. - se añaden medidas a todas luces inoperantes, tales como el cubrir a los ahogados con estiércol para ayudar a su reanimación ${ }^{(66)}$, las friegas y sangrías, etc. Un método tan acertado como la respiración boca a boca ${ }^{(67)}$, por citar otro caso concreto, aparece, sin cobrar mayor relevancia, al lado de prácticas tradicionales de improbable fundamento científico y nula eficacia.

La idea de que el fin puede justificar los medios parece prevalecer, sin duda, en esta vertiente del Canónigo encaminada a prestar toda una serie de servicios en materia de sanidad a sus semejantes.

Esta cuestión se advierte de manera clara en su auténtica obsesión por combatir, entre todas las enfermedades que aquejaban a sus conciudadanos, las relacionadas con los ahogos, asfixias y apoplejías. Al margen de su sensibilización por el tema - provocada por las lecturas citadas - tres eran, a nuestro parecer, los motivos próximos que le impulsaron a luchar contra ellas y no contra otros males como las fiebres palúdicas, por ejemplo, que asolaban su comarca. En primer lugar estaba el peligro cierto y constante del río Segura que atravesaba la ciudad y que, disperso en una compleja red de acequias y canales se extendía por toda su huerta. El cobro de vidas humanas a cambio de la riqueza que propocionaba no era sólo debido a las frecuentes riadas y desbordamientos ocasionados por sus aguas en las épocas de lluvias torrenciales - primavera y otoño, principalmente. Durante los largos meses de estío los accidentes por ahogo no faltaban y el problema preocupaba a las instituciones ciudadanas. El propio D. Marcelo hace alusión a determinadas desgracias concretas ${ }^{(68)}$ y las medidas preventivas del Colegio de Predicadores o del Seminario conciliar prohibiendo a sus colegiales bañarse en el río, refuerzan una preocupación que el Canónigo hacía suya. Estaba, además, una cuestión de orden estrictamente religioso: poder dar la extremaunción, tras el previo acto de contricción, a cuantos caían víctima de estos y otros percances similares ${ }^{\left({ }^{69}\right)}$. Por último había una poderosa razón que, no debe extrañarnos, quizá fuese la causa originaria de toda la preocupación y celo de D. Marcelo: la muerte de su madre a causa de un insulto apoplético ${ }^{(70)}$. Este hecho, 
narrado a Mayans en una de sus cartas, había marcado profundamente a nuestro personaje, hasta el punto de llegar a convertirle en un auténtico hipocondríaco con respecto al tema. A pesar de no tener miedo a la muerte, según decía, por hallarse "penetrado de los principios de la Filosofía de Epícteto y Focílides» (71), aseguraba sentir verdadero pánico por la apoplejía debido a que podían enterrarle vivo ${ }^{(72)}$. Obsesionado por ello, todas las noches, al acostarse, rezaba una oración especial que le habían enseñado los Padres de San Vicente Paul del Seminario de Barcelona y, acto seguido, añadía el «a subitanea, et improvisa morte libera nos Domine» ${ }^{(73)}$ que cantaba la Iglesia en sus letanías mayores. El temor al accidente había especializado a D. Marcelo en muchos de los síntomas y causas que podían originarlo, tal y como se desprende de algunas de sus consideraciones: «...la menor cozquilla que haga la circulación de la sangre, o algún flatillo pasagero, me ponen en vela, y como de susto...» ${ }^{(74)}$ Para evitar el peligro, o la desazón, procuraba huir, siempre que lo podía, tanto de «los excesos en las comidas y cenas» como del «...que nadie me dé pesadumbres...» (75)

No resulta exagerado, por lo tanto, atribuir a sus problemas personales la preocupación por la apoplejía, los ahogos por agua y las asfixias. Máxime si tenemos en cuenta que el Canónigo consideraba que las dos últimas desgracias podían provocar, también en ocasiones, el estado de «muerte aparente», para el que las autoridades no habían establecido aún - según se quejaba - una adecuada legislación encaminada a dilatar el tiempo comprendido entre los accidentes y los entierros ${ }^{(76)}$. Los remedios que no dudaría en aplicarse a sí mismo con el fin de evitar el motivo de sus temores, los hacía extensivos a sus semejantes sin que prevaleciese otra razón que sus ansias curativas.

Parejo al afán de prevenir y de curar corría en D. Marcelo el deseo de ser claro en los escritos que anunciaban sus proyectos como paso previo a su puesta en práctica; es decir; su afán divulgador. Para conseguir este propósito - siguiendo, como confesaba, al maestro Luis Vives en sus presupuestos didácticos tendentes a despertar el interés de los lectores ${ }^{(77)}$ _ el Canónigo no dudó en recurrir a una serie de licencias literarias quizás poco ortodoxas en el campo de divulgación médica. En su Junta de Piedad... ya había intentado el artificio de comenzar mediante «...un Prólogo jocoso, aunque por otra parte útil, e instructivo, no sólo en lo moral sino también en lo físico.... ${ }^{(78)}$ que llamase la atención de sus conciudadanos sobre un problema que sabía árido y aburrido. Pero la experiencia fue más lejos en El Espudeo... - obra que venía a ser la continuación de la anterior. Aquí, D. Marcelo, para glosar el texto íntegro de un folleto publicado sobre otra Máquina Fumigatoria promocionada por unos médicos de la Sociedad Económica de Amigos del País de Mallorca ${ }^{(79)}$, y avalar así la utilización de la que él había mandado fabricar, no dudó en dar a su escrito la forma y argumento de un Sueño ${ }^{\left({ }^{(8)}\right)}$. Admirador de Quevedo y de Torres Villarroel recurrió a esta licencia genérica y soñó un viaje a los infiernos en donde el encuentro con las almas de ahogados, axfíticos, ahorcados, etc., le sirvió de pretexto para defender los remedios que preconizaba contra estos males y que coincidía en muchos aspectos con aquellos auspiciados por los médicos mallorquines. Médicos que habían sabido obrar muy bien - decía D. Marcelo- porque habían publicado un 
folleto explicativo en dos columnas, una en castellano y otra en mallorquín, con el fin de que incluso «...los más rústicos del campo pudieran instruirse» ${ }^{(81)}$

Por supuesto que el Canónigo oriolano estuvo lejos de igualar el talento creador de los escritores que había tomado como modelo. Su estilo excesivamente pesado, un ingenio sólo discreto y su escasa inventiva no sabemos hasta qué punto hubieran logrado llevar al lector hacia la «trampa» de la instrucción de no haber sido un autor local el artífice de tamaña aventura. Pero no es éste el lugar apropiado para tratar un aspecto que sería más propio de la crítica literaria. Lo que aquí nos importa, en realidad, es resaltar la firme voluntad del Canónigo por alcanzar la eficacia comunicativa y hacer con ella posible la aceptación de sus proyectos.

\section{LA MÁQUINA FUMIGATORIA DE D. MARCELO MIRAVETE}

¿Cuáles eran, en resumidas cuentas, los proyectos que nuestro personaje intentaba divulgar para remedio de los accidentados por ahogo y asfixia»?, ¿para «restituir a la vida» a cuantos morían en el estado de «muerte aparente»?

En primer lugar la solución arbitrada era la de generalizar el uso de una Máquina Fumigatoria en las operaciones de reanimación de aquellos que pudieran sufrir este tipo de desgracias. A la descripción del aparato y a las instrucciones para su manejo iba dedicada la mitad de su opúsculo Junta de Piedad..., donde se cantaban también las excelencias del empleo complementario del Alkalí volátil como fármaco casi milagroso.

No se trataba, en modo alguno, de un invento del Canónigo oriolano. Máquinas de idénticas o similares características a la mandada construir por él, existían ya en muchos puntos de España y su uso, al parecer, estaba más generalizado de lo que pueda suponerse. Ciertas notas contenidas en El Espudeo... nos hablan de la existencia de uno de estos artefactos en Holanda hacia 1768 y del éxito de su empleo en las tareas de reanimación de ahogados ${ }^{(82)}$. En uno de los Extractos de las actividades anuales desarrolladas por la Real Sociedad Económica Bascongada de Amigos del País, parece confirmarse la noticia al hablársenos de la utilización de uno de estos aparatos en Amsterdam en una época anterior a

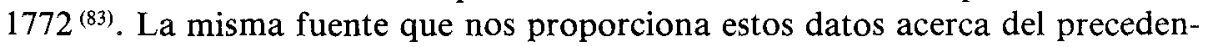
te europeo, hace referencia al empleo de una Máquina en Sevilla en 1773 y de la decisión de los médicos de la Real Sociedad Económica Bascongada por realizar experimentos con otra en $1775^{(84)}$.

Fue probablemente en la década de 1770-1780 cuando la preocupación por el socorro de los percances que tratamos comenzó a generalizarse en España preparando el terreno para el uso de las Máquinas. En 1775, por ejemplo, el médico valenciano Cristóval Fabregat hacía imprimir por Francisco Burguete, un pequeño librito en cuarto, de 62 páginas, cuyo título no puede ser más elocuente: Discurso Médico-práctico para socorrer y revocar a sus sentidos, los ahogados, ahorcados, helados y sufocados por el tufo del carbón, de la cal, de las velas de sebo $y$ de otras exalaciones perniciosas, ilustrado con historias verdaderas de autores gravísimos $^{(85)}$. Dicho trabajo, con la ampliación de un apéndice médico-moral, 
era objeto de una nueva edición en $1776^{(86)}$, no siendo ésta, probablemente, la última vez que fue llevado a la imprenta. Por las mismas fechas, en 1777, el Doctor D. Joseph Ignacio Santpons, Socio-Secretario primero de la Real Academia Médico-Práctica de Barcelona y uno de los fundadores de la misma ${ }^{(87)}$ publicaba otro tratado sobre las «muertes aparentes», dedicando ya un apartado a la descripción y utilización con fines terapéuticos de «...una máquina para introducir el humo del tabaco, tan manual y portátil, que cualquiera puede traerla consigo») ${ }^{(88)}$ Años más tarde, en 1784, el primer libro publicado a expensas de la Academia catalana se dedicaba todavía a la prevención y asistencia de los accidentes que tratamos ${ }^{(89)}$.

Sobre el personaje de Santpons hemos de detenernos un instante. Su labor divulgadora, a nivel nacional, defendiendo el empleo de las Máquinas fue, por lo que sabemos, de gran importancia. Hombre de espíritu filantrópico - del que probablemente D. Marcelo tendría noticias a través de sus lecturas-Santpons, no contento con la publicación de su tratado, mandó insertar en la Gaceta de Ma$d r i d$, en 1778, un anuncio concediendo un premio de 30 pesos «para el primero que restituyese la vida (dentro de España) a un ahogado, o acometido de qualquiera de las muertes aparentes» ${ }^{\left({ }^{90}\right)}$. La noticia, caída ya sin duda sobre campo abonado, no hizo esperar sus efectos, a juzgar por las respuestas que hemos podido recopilar. En junio de ese mismo año se hacía llegar hasta el médico barcelonés el éxito obtenido por un cirujano de Llombay (Valencia) que el día 6 de mayo de 1778 «...aviendo caido en una balsa de agua una criatura de 22 meses, i sacadose de ella sin señales de vida, con el humo del tabaco se la avia vuelto a su ser» ${ }^{(91)}$. Santpons pedía a las autoridades de Llombay las certificaciones adecuadas para hacer llegar el premio a dicho cirujano, ya que tenía conocimientos de que el personaje en cuestión no podía hacerlo por tratarse de sujeto «...que apenas save poner su firma» ${ }^{\left({ }^{22}\right)}$ Las certificaciones no debieron llegar porque el premio fue adjudicado a otro cirujano, esta vez de Cartagena; D. Antonio Ortiz, que había salvado por el procedimiento indicado a dos personas ${ }^{(93)}$.

Probablemente no fueron estos los dos únicos candidatos al galardón ofrecido por el médico barcelonés. $\mathrm{O}$, si lo fueron, la práctica del método por él preconizado - que hacía necesario el uso de la Máquina, como veremos- no tardó en extenderse tal y como evidencia la publicación de otro folleto en 1779. Éste, realizado por los doctores D. Joseph Llabrés, D. Joaquín Jaquotot y D. Rafael Evinent, fue impreso en Mallorca y auspiciado por la Sociedad Económica de Amigos del País de aquella ciudad con la intención de divulgar el conocimiento de otra Máquina Fumigatoria ${ }^{(94)}$.

No sabemos con exactitud de dónde le vino la idea a D. Marcelo para ordenar construir uno de estos aparatos y divulgar su empleo en Orihuela. Aunque es posible que tuviera noticias de Santpons a través de sus lecturas de la Gaceta de Madrid, todo nos hace pensar que el fundamento del proyecto le vino de sus contactos con la Academia Médico Gaditana de la que era, como dijimos más arriba, socio de erudición y mérito. Decimos esto porque fue precisamente en Cádiz donde el Canónigo mandó construir su Máquina por tener noticia de que en esta ciudad se había fabricado una para uso específico de los cirujanos de la Real Armada y Arsenales ${ }^{(95)}$. Sea como fuere, el caso es que para 1788, probablemen- 
te, D. Marcelo contaba ya con su ingenio y estaba dispuesto a darlo a conocer a los oriolanos.

¿Cómo era exactamente el artilugio mandado construir por nuestro personaje? No se trataba en modo alguno de un aparato complicado. Aunque el Canónigo, por un exceso de pudor más propio de su condición de eclesiástico que del espíritu avanzado que pretendía ser, ordenó que no se publicasen las láminas en que de modo gráfico se explicaba su funcionamiento - sería «un gasto ocioso y que además las pinturas ofenderían la vista» ${ }^{(96)}$ dijo- resumió en su Junta de Piedad... las características del aparato y su funcionamiento siguiendo las instrucciones que en folleto adjunto le enviaron desde Cádiz.

La Máquina en cuestión constaba de un fuelle que unido mediante un tubo a una especie de pipa o cazoleta, en cuyo interior se consumía tabaco habano, acababa a su vez en otro conducto rematado por una cánula que debía introducirse en el ano de los ahogados o axfíticos ${ }^{(97)}$. De aquí, sin duda, el pudor de nuestro hombre, que confiaba sólo las tablillas gráficas a los médicos que utilizaran el invento, y también su preocupación por incorporar mujeres a su Junta de Piedad para el caso de que las víctimas fuesen del sexo femenino ${ }^{(98)}$. La acción de la Máquina consistía en impulsar el humo del tabaco por vía rectal y hacerlo viajar a lo largo de los intestinos. El principio en que se fundaba la utilidad del procedimiento, según el Canónigo, que debía basarse en el folleto enviado por los cirujanos gaditanos, era el siguiente:

«...el buen efecto que produce la Máquina resulta de la acción mecánica del Ayre sobre el diafragma; porque empujado éste por el que entra con el humo por los intestinos, comprime los pulmones, y obliga a salir por la Trachea al que se halla contenido en ellos; y contrarrestando esta fuerza expulsiva la columna de ayre exterior o de la Atmósfera, vuelve a entrar en ellos y se forma la respiración...» (99)

No se reducía, sin embargo, toda la acción curativa al empleo de la Máquina pura y simplemente. Una serie de medidas complementarias debían de regular y acompañar su uso. Decía D. Marcelo, por ejemplo, que mientras fuese introducido el humo en el cuerpo del paciente, éste debía ser mantenido de lado y movido con suavidad durante la operación. Debía auxiliársele, en el instante en que comenzaran los primeros síntomas de recuperación, con el alkalí volátil. Una cucharada de agua con 4 ó 5 gotas del producto completarían la acción curativa ${ }^{(100)}$. Incluso antes de que entrase en funcionamiento la Máquina se depositaban en el fármaco grandes esperanzas de éxito, en especial si su aplicación en la nariz y boca del accidentado era acompañada de una serie de friegas de alcanfor o aguardiente con el fin de «promover la oscilación de los vasos capilares sanguíneos) ${ }^{(101)}$.

Aunque la fe depositada por el Canónigo en los efectos del aparato era ciega - hasta el punto de llegar a reglamentar que permitiría prestarla para su empleo a los accidentados de Murcia y de Elche, localidades situadas a más de $20 \mathrm{~km}$. de Orihuela - debemos recordar que no por ello olvidaba nuestro personaje el empleo de los métodos más dispares que había recopilado a lo largo de sus lecturas. Sería excesivamente prolijo enumerarlos ahora. En El Espudeo... se recoge 
una auténtica antología de este tipo de remedios que aparecen más tarde sistematizados en un curioso apéndice de términos que remata la parte correspondiente al Sueño ficticio. Ya hemos adelantado que se trata de una acumulación de conocimientos y noticias con poco sentido crítico en la que abundan antiguos métodos caseros y prácticas muy próximas a la superstición.

Resulta más interesante hacer hincapié en el tema del alkalí volátil. El producto, en la última década del siglo XVIII era todavía muy difícil de conseguir en Orihuela. D. Marcelo se vanagloriaba poco menos de haber sido su introductor en la ciudad. Lo había hecho traer desde Madrid para ponerlo a disposición de la Junta de Piedad que se apresuraba a fundar para socorro de los ahogados. Teniendo, no obstante, algunos frascos de sobra, se había comprometido a surtir desinteresadamente a algún boticario de la ciudad siempre que, dada la rareza y costo del producto, se despachase - previa receta médica - sólo a quienes sufriesen un insulto apoplético y no a quienes padeciesen simplemente del mal ${ }^{(102)}$. El uso del alkalí, concluía D. Marcelo, era el complemento ideal de su Máquina - la más perfeccionada de todas, según él- y un remedio más moderno y eficaz que el empleo de la sal amoníaco utilizada hasta la fecha como aditamento del resto de los aparatos existentes en España.

\section{LA JUNTA DE PIEDAD: UN PRECEDENTE DE LAS SOCIEDADES DE SALVAMENTO Y SOCORRISMO}

La otra idea preventiva de D. Marcelo consistía en la fundación y financiación a sus expensas de una Junta destinada a la custodia de la Máquina y a las acciones de salvamento y primeros auxilios de cuantos cayeran al río o a los numerosos canales y pozos que existían en la huerta. Los estatutos que debían regular la constitución de esta sociedad, así como las personas que debían integrarla y sus funciones dentro de la misma, se encuentran expuestas en la segunda parte del opúsculo Junta de Piedad...

Se trataba de un proyecto que tenía ya algunos precedentes europeos. Que sepamos, un plan de características similares había cuajado en París hacia $1750^{(103)}$. Allí el farmacéutico Pía había creado una serie de estaciones distribuidas a lo largo del Sena para socorrer a quienes caían en sus aguas.

La fundación de la Junta de Orihuela, salvo quizás en el número de sus componentes, poco tendría que envidiar a la parisina en lo que se refiere a organización y minuciosidad en los cargos y funciones. El personal que debía integrarla estaría compuesto por dos Médicos Titulares, un Cirujano Director de la Máquina y Operación, dos Ayudantes Cirujanos, tres hombres que cumplirían la triple misión de Convocadores, Hacheros y Conductores del Ahogado, cuatro Nadadores y un Celador ${ }^{(104)}$. Todos los miembros serían retribuidos mediante anualidades fijas cuyo pago no excluía una curiosa tabla de propinas para el caso en que las operaciones de salvamento y socorrismo fuesen consumadas con éxito. Los salarios, cortos, según D. Marcelo, pero no tanto si se tenía en cuenta que un médico de la ciudad cobraba por curar durante todo el año a una familia de 8 a 10 libras, eran los siguientes: 75 reales a cada médico, 100 reales al Cirujano 
Director, 5 y 3 libras respectivamente a cada uno de los Cirujanos Ayudantes, 5 libras a quienes cumplian la triple misión aludida, 60 reales a cada Nadador y 120 reales al Celador ${ }^{(105)}$. El privilegio de estar exentos de albergar tropa se añadía a estos salarios.

La misión a cumplir por cada uno de estos cargos y los individuos que fueran elegidos para desempeñarlos fue, en síntesis, la siguiente: los Médicos Titulares debían de reunir una serie de condiciones para proceder adecuadamente al cuidado de los accidentados. A juicio del fundador éstas serían: «...pericia en la Medicina práctica, la compasión y caridad con los desgraciados que les facilite la paciencia, para sufrir la vista lo poco agradable, y tal vez otras molestias que les presentara la operación con la Máquina Fumigatoria.... ${ }^{(106)}$. Se nombraba para ambos puestos al Dr. D. Joseph Ruiz, médico de la Ilustre Ciudad - que ya había experimentado en cierta ocasión la Máquina con éxito ${ }^{(107)}$ - y al Dr. D. Sebastián Barceló, catedrático de Anatomía de la extinta facultad médica oriolana ${ }^{(108)}$. Sobre el cirujano D. Joseph Salom - colaborador del Dr. D. Joseph Ruiz en el experimento anterior con la Máquina - recaía el cargo de Cirujano Director, con la misión estricta de «...armar y desarmar la Máquina» ${ }^{(109)}$, y de ser el brazo ejecutor de todas las operaciones que se realizasen con ella. Dos cirujanos, D. Andrés Lucas de Albarez, del Colegio de Cirugía de Cartagena, y D. Jerónimo Lapuente, le ayudarían en estos menesteres ${ }^{(110)}$. Los tres personajes con pluralidad de funciones - Convocadores, Hacheros y Conductores- debian de pertenecer a barrios distintos con el fin de cumplir con mayor eficacia sus cometidos. Fueron elegidos por D. Marcelo, Vicente Orgiles, del Arrabal Roig, Joseph Pardines, del barrio de San Agustín - con responsabilidades también sobre el «casco de la ciudad»- y Miguel Rabay, del Arrabal de San Juan ${ }^{(111)}$. Su misión consistiría en avisar de inmediato, cuando se produjese el accidente, tanto al Justicia del distrito como a los nadadores. Acto seguido se avisaría a los restantes componentes de la Junta. A continuación, en el caso de que el suceso tuviese lugar de noche, se proveerían de hachas de viento y portarían hasta el lugar del accidente tanto una silla de mano - especialmente construida para portar al ahogado- como el resto del material necesario para la operación de salvamento: cuerdas, una sábana de esparto con agarraderas para sacar a la víctima, etc. Su trabajo finalizaría con la conducción del enfermo hasta el lugar donde debía ser intervenido por los médicos y cirujanos.

No creemos que sea necesario mencionar cuál era la misión de los nadadores. Digamos que, a juicio del Canónigo, debían ser «...personas diestras en nadar, y que puedan mantenerse lo preciso debaxo del agua», pero, también, personas $«$...prontas a toda hora que se les convoque, para echarse a nadar, y buscar al desgraciado, ya sea en el Río, ya en las Azequias» ${ }^{(13)}$. Por último, sobre el Alguacil Mayor de la ciudad recayó el cargo de Celador, cuya tarea consistía en vigilar que todos cumplieran con eficacia las tareas asignadas ${ }^{(114)}$.

Pocos detalles quedaron sin hilvanar en el proyecto. Desde los aspectos más nimios - como el que regulaba el atuendo decente para los nadadores - hasta los más complejos - la demostración pública de un simulacro de salvamentoy toda una serie de recursos para situaciones imprevistas - accidentes en pozos, 
salvamentos en invierno, etc.- aparecieron registrados en el Reglamento de la Junta, corroborando así la seriedad del proyecto y el sentido eminentemente práctico del mismo.

No podemos resistir la tentación de dar noticia - aunque sea de pasadade la jornada en que D. Marcelo, para someter a prueba a sus nadadores, organizó un simulacro de salvamento y socorrismo en las aguas del Segura. La tarde del 6 de julio de 1788, en «presencia del Señor Gobernador, Real Justicia, y concurso notable... ${ }^{(115)}$ fue lanzado a las aguas del río un hombre de madera, convenientemente lastrado y provisto incluso de cabellos, que debía ser buscado por los nadadores y llevado hasta la orilla. Esta acción, colofón de otra serie de actos de exhibición de los nadadores, no fue todo lo feliz que se esperaba. El lecho del río jugó una mala pasada al muñeco, que quedó sepultado en el lodo. Los socorristas tardaron más de tres horas en dar con él, y la función, a juicio del Canónigo, quedó un tanto deslucida. El acto, sin embargo, no desagradó a la concurrencia y tanto las autoridades municipales como el cabildo catedralicio felicitaron con gran efusión al Canónigo e hicieron constar en sus respectivos libros de actas ei agradecimiento al filántropo local. D. Marcelo, en justa correspondencia, concedió al Ayuntamiento oriolano, a título honorífico, la propiedad de la Máquina y sus enseres así como el derecho a tutelar la Junta cuando él muriese ${ }^{(116)}$. Todo fueron parabienes, entre los cuales no faltó la felicitación del rey y de Floridablanca, previamente enterados del proyecto ${ }^{(117)}$. Incluso el cónsul inglés de Cartagena, Mr. Patricio Wilson, cursó viaje con otros caballeros hasta Orihuela en octubre de 1791 para informarse directamente acerca de la Máquina y los pormenores de su fabricación y funcionamiento ${ }^{(118)}$.

\section{CONCLUSIONES}

Queda por establecer cuáles fueron los efectos que sobre la sociedad oriolana tuvieron estas medidas preventivas. Los datos que poseemos sobre el particular son escasos. Sabemos que tanto la Máquina como la Junta llegaron a funcionar entre 1788 y 1792. Tenemos noticia, asimismo, de que en la primera fecha citada D. Joseph Ruiz y el cirujano D. Joseph Salom, utilizaron con éxito el aparato. Pero poca cosa más cuentan los documentos consultados. Es probable que la muerte del Canónigo - en las navidades de 1792 - restase vida también a una fundación que sufragaba a costa de su bolsillo. Un acta del Ayuntamiento registra la aceptación por parte de este organismo de la Máquina y sus enseres cumpliéndose así la voluntad de D. Marcelo ${ }^{(119)}$. Pero de aquí a la responsabilización municipal de los gastos de la Junta va un trecho sobradamente conocido por cuantos saben de la penuria crónica de las arcas ciudadanas en aquella época. Probablemente la Junta desapareció y la Máquina, salvo una que otra esporádica salida, quedaría olvidada en alguna dependencia de la Casa Consistorial. El proyecto y su puesta en práctica fue, como debemos suponer para otros intentos similares, de corta vida; pero fue un anuncio, quizás, de que los tiempos estaban cambiando, de que realizaciones nuevas e insospechadas se atrevían a combatir contra viejos enemigos considerados antes como irreductibles. 
D. Marcelo en El Espudeo..., con sorna y buen humor, dejó escrito lo siguiente acerca de las propiedades de su Máquina:

«Pero veas, Lector, una virtud no descubierta hasta ahora de mi Máquina Fumigatoria, y demás prevenciones para restituir a el uso de la vida á los que se ahogaren; y es la de haber causado a la gente mucho miedo de arrojarse al agua. Yo escribo esto en 22 de septiembre; y quando en semejante tiempo llevamos dos, o tres ahogados, en este año no ha habido ni siquiera uno de estos desgraciados, ni en la Ciudad, ni en sus cercanías, como me ha asegurado el silencio, que no hubiera en el caso contrario, pues todos esperaban ver uno de estos temibles casos. Ha podido también aumentar la cautela el haber visto todo el Pueblo, que seis nadadores no pudieron hallar el hombre de madera que hice arrojar a la caxa del rio para la prueba del 6 de julio; mas vale preservarlos de ahogarse, que restituírlos a la vida después de ahogados... Solo si, les ruego, que si alguno se resuelve a dexarse ahogar, sea donde no hayga tanto lodo y fagina como en el buque del rio que esta dentro de la Ciudad...» ${ }^{(120)}$ 


\section{NOTAS}

* Este artículo ha sido elaborado a partir de la síntesis de dos comunicaciones que fueron presentadas al VII Congreso de Historia de la Medicina celebrado en Alicante en abril de 1983, bajo los títulos de «D. Marcelo Miravete de Maseres. Noticia sobre un ilustrado de provincias en la Orihuela del siglo XVIII» y «La Máquina Fumigatoria y la Junta de Piedad de D. Marcelo Miravete de Maseres. Dos proyectos de prevención médico-sanitaria en la Orihuela del siglo XVIII».

(1) Véase, entre otras obras de estos autores, las siguientes: RAMÓN CEÑAL: «La filosofía española del siglo XVII», en Rev. Univ. Madrid, n. ${ }^{\circ} 11$, Madrid, 1962, pp. 373-410; OLGA QUIROZ: La introducción de la filosofía moderna en España, México, 1949; VICENTE PESET, «El Doctor Zapata y la renovación de la Medicina en España», en Arch. Iber. Hist. Med., n. ${ }^{\circ} 14,1962$, pp. 133-206; J. M. LÓPEZ PIÑERO, La introducción de la ciencia moderna en Esaña, Barcelona, 1969; S. GARCÍA MARTÍNEZ, Els fonaments del País Valencià Modern, Valencia, 1963; ANTONIO MESTRE, Despotismo e Ilustración en España, Barcelona, 1976.

(2) FRANÇOIS LÓPEZ: «Rasgos peculiares de la Ilustración en España» en Mayans y la Ilustración, Actas del Simposio Internacional en el Bicentenario de la muerte de Gregorio Mayans, Valencia, 1981, vol. II, pp. 629-671.

(3) Ibid. pp. 635-636.

(4) GILLO DORFLES: Símbolo, comunicación y consumo, Barcelona, $196 \mathrm{pp}$.

(5) JEAN SARRAILH: La España Ilustrada de la segunda mitad del siglo XVIII, Madrid, 1974, pp. 122-123.

(6) RICHARD HERR: España y la revolución del siglo XVIII, Madrid, 1979, pp. 35-38.

(7) La idea de adoptar este calificativo nació a raíz de la lectura de JUAN ANTONIO MARAVALL, «El primer siglo XVIII y la obra de Feijóo» en II Simposio sobre el Padre Feijóo y su siglo, Oviedo, 1976, pp. 151-195. Aunque este autor consideraba cuatro niveles a la hora de hacer referencia a los contenidos en el proceso de comunicación, por motivos de simplificación, hemos tratado de unificar los niveles por él denominados $\langle\mathrm{c} » \mathrm{y}$ «d» en lo que hemos llamado «tercer nivel».

(8) JORDI NADAL: La población española (siglos XVI al XX), Barcelona, 1971, p. 94.

(9) Agradecemos esta información a D. ANTONIO GALIANO que en la actualidad se encentra escribiendo una biografía sobre el personaje.

(10) Archivo Histórico de Orihuela, Sala de Protocolos. Legajo: «Títulos y Méritos, Relación de títulos y méritos de D. Marcelo Miravete de Masseres».

(11) JUSTO PASTOR FUSTER: Biblioteca Valenciana de los Escritores que florecieron hasta nuestros dias $y$ de los que viven aún con adiciones y enmiendas a la de D. Vicente Ximeno, Valencia, 1830, vol. II, p. 133.

(12) Archivo Histórico de Orihuela, Sala de Protocolos. Legajo: "Títulos y Méritos. Relación...

(13) JUSTO PASTOR FUSTER: Op. cit., pp. 133-134.

(14) Archivo Histórico de Orihuela, Arm. n. ${ }^{\circ} 159$. «Libro de Grados y Acuerdos de la Universidad de Orihuela, años 1773-1776», fols. 563v-566r. 
(15) MARCELO MIRAVETE DE MASERES: Junta de Piedad y Compasión para socorro de los ahogados, y de los que caen con aparente muerte repentina. Ideada, y llevada a efecto a sus expensas en beneficio de su patria la Ciudad de Orihuela, por el Doctor... Imprenta Viuda de Felipe Teruel, Murcia, 1791. (Esta obra consta de 39 páginas en folio. Las páginas 1-12, respectivamente, constituyen un prólogo en el que se hace la descripción de la Máquina Fumigatoria, mientras que el resto se dedica a la exposición de los detalles relacionados con la Junta de Piedad).

(16) JUSTO PASTOR FUSTER: Op. cit., pp. 133-134.

(17) Parte de esta correspondencia se encuentra en el Archivo Municipal de Valencia. Sección: Serrano Morales, «Cartas de Mayans», Caja n. ${ }^{\circ} 36$ (Sig. 7272-36). El resto de las cartas pertenece al Fondo de la Familia Alegre y nos fue facilitada su consulta por medio del Dr. D. Antonio Mestre Sanchís.

(18) JUSTO PASTOR FUSTER: Op. cit., pp. 133-134.

(19) Ver referencia completa en nota $n .^{\circ} 15$.

(20) Esta obra, cuyo título completo queda expuesto, de formato en $4 .^{\circ}$, consta de 6 hojas +124 páginas con numeración romana. Las 6 hojas corresponden a una «Advertencia del Editor al Lector». Las I-IV al «Prólogo». Las IV-XCI corresponden al texto del «Sueño Moral» que lleva por título El Espudeo... Las numeradas entre XCII-CXXI, ambas inclusive, contienen un «Índice alfabético de términos empleados», y las CXXII-CXXIV a un «Apéndice». La edición no presenta fecha, pero debió imprimirse entre octubre de 1791 y octubre de 1792, año, este último en que murió su autor. Ello se deduce de que es obra posterior a la Junta de Piedad..., y de que el propio D. Marcelo en el n. ${ }^{\circ} 16$ de El Correo de Murcia, correspondiente al 23-X-1792, en la página 127, hace alusión a la publicación de El Espudeo... como hecho ya consumado.

(21) JUSTO PASTOR FUSTER: Op. cit., p. 134.

(22) Hemos localizado en la Biblioteca Pública Provincial de Alicante dos impresos más de este autor. La más triunfante y benéfica Aurora María Santissima con esta invocación. Oración Panejyrico-moral que en la fiesta anual consagrada por su Cofradia (sita en la Hermita de los Ángeles de la villa de Elche) dixo el señor Doctor D. Marcelo Miravete de Maseres. Murcia, Felipe Teruel, 1767,10 hojas + 23 páginas. Y Novena a Nuestro Padre Jesús Nazareno que se venera en Orihuela, que compuso el Dr. D. Marcelo Miravete de Maseres. 1961 (sin pie de imprenta). 32 páginas. Se trata de una de las muchas reimpresiones que se han hecho sobre este texto cuya fecha original de composición desconocemos.

(23) MARIO MARTÍNEZ GOMIS: «Notas sobre tensiones y violencia interclerical en la Orihuela del siglo XVIII» en Actas del II Congreso de Historia Moderna de la Corona de Aragón, Pau, 1981 (en prensa).

(24) MARIO MARTÍNEZ GOMIS: «Aportación al estudio de la financiación y rentas de una Universidad Menor: Orihuela, siglos XVII y XVIII» en Mayans y la Ilustración..., pp. 429-466.

(25) Archivo de la Catedral de Orihuela. «Expediente sobre el Seminario, año 1784».

(26) MARCELO MIRAVETE DE MASERES: Junta de Piedad..., p. 11.

(27) MARIO MARTÍNEZ GOMIS: «Notas sobre tensiones...»

(28) DAVID BERNABÉ GIL: Tierra y sociedad en el Bajo Segura (1700-1750), Alicante, 1982.

(29) Fondo Familiar Alegre. «Carta de D. Marcelo Miravete a D. Gregorio Mayans de 21-12-1773»).

(30) Ibid. «Carta de octubre de 1771».

(31) MARCELO MIRAVETE DE MASERES: El Espudeo..., p. XII.

(32) Ibid., p. CX.

(33) Ibid., p. III.

(34) Ibid., p. LI.

(35) Ibid., pp. XLVI, LIV, XCVIII-XCIX, CVI-CVII.

(36) Ibid., p. XIV. 
(37) Ibid.

(38) Fondo Familia Alegre. «Carta de D. Marcelo Miravete a D. Gregorio Mayans, de 20-1-1772».

(39) MARCELO MIRAVETE DE MASERES: El Espudeo..., p. XXIX.

(40) Fondo Familia Alegre. «Carta de D. Marcelo Miravete a D. Gregorio Mayans de 20-1-1772».

(41) Ibid.

(42) Ibid.

(43) Ibid.

(44) Ibid.

(45) Ibid., «Carta de 14-2-1772».

(46) Ibid.

(47) Ibid.

(48) Ibid.

(49) MARCELO MIRAVETE DE MASERES: Junta de Piedad..., pp. 8 y 9.

(50) El Correo de Murcia, n. ${ }^{\circ}$ 13, sábado 13 de octubre de 1792, p. 102.

(51) ERWIN H. ACKERKNECHT: «Medicina y sociedad en la Ilustración» en Historia Universal de la Medicina dirigida por P. LAIN ENTRALGO. Tomo V. «Ilustración y Romanticismo», Barcelona, 1976, pp. 143-151.

(52) J. A. MARAVALL: Op. cit., p. 152.

(53) MARCELO MIRAVETE DE MASERES: El Espudeo..., p. XXI.

(54) ERWIN H. ACKERKNECHT: Op. cit., p. 144.

(55) Ibid., p. 146.

(56) Ibid., p. 147-148.

(57) Ibid., p. 147.

(58) Ibid., p. 148.

(59) PEDRO LAIN ENTRALGO, AGUSTÍN ALBARRACÍN TEULÓN, DIEGO GRACIA GUILLÉN: «La fisiología de la Ilustración» en Historia Universal de la Medicina..., Tomo V, pp. 45-60, p. 56.

(60) Las referencias de D. Marcelo sobre la obra del P. Feijóo son mucho más abundantes que las citas de Solano o del Setabense.

(61) MARCELO MIRAVETE DE MASERES: El Espudeo..., pp. LXXVII y CXI.

(62) MARCELO MIRAVETE DE MASERES: Junta de Piedad..., p. 17-18; El Espudeo..., pp. XV, XLI, XCIII, CXI.

(63) MARCELO MIRAVETE DE MASERES: El Espudeo..., p. CVI.

(64) Ibid., p. XLVIII.

(65) Ibid., pp. LXVII-LXVIII.

(66) MARCELO MIRAVETE DE MASERES: Junta de Piedad..., p. 14.

(67) Ibid., p. 18.

(68) Ibid., pp. 14, 24 y 25.

(69) Fondo Familiar Alegre, «Carta de D. Marcelo Miravete a D. Gregorio Mayans, de 4-1-1777».

(70) MARCELO MIRAVETE...: Junta de Piedad..., pp. 32-33.

(71) Ibid., 32.

(72) Ibid.

(73) Ibid. 
(74) Ibid.

(75) Ver nota n. ${ }^{\circ} 65$.

(76) MARCELO MIRAVETE...: El Espudeo..., «Advertencia del Editor...», s/n.

(77) MARCELO MIRAVETE...: Junta de Piedad..., p. 1.

(78) MARCELO MIRAVETE...: El Espudeo..., «Advertencia...», s/n.

(79) Ibid.

(80) Ibid.

(81) Ibid., p. XCV.

(82) Debemos esta información a la gentileza de la profesora $D .{ }^{a}{ }^{M} \cdot{ }^{a}$ ISABEL LOBO SATUE, que en el coloquio a esta comunicación nos ofreció los datos reseñados.

(83) Ibid.

(84) M. ${ }^{a}$ LUZ LÓPEZ TERRADA: La literatura científica en la Valencia de la llustración (17001808), Tesis de Licenciatura inédita, Dpto. ${ }^{\circ}$ de Historia Moderna de la Facultad de Filosofía y Letras de la Universidad de Valencia. Valencia, 1982, fols. 92-94.

(85) Ibid., p. 93.

(86) JUAN SEMPERE Y GUARINOS: Ensayo de una Biblioteca de los mejores escritores del reinado de Carlos III, Madrid, 1789, Tomo V y VI, p. 105.

(87) Ibid., pp. 102-103. El título de la obra en cuestión era el siguiente: Disertación MédicoPráctica, en que se trata de las muertes aparentes de los recién nacidos y de los medios para revocarles a la vida. En el fin de ella se da la descripción de una máquina para introducir el humo del tabaco, tan manual y portátil que cualquiera puede traerla consigo. En Barcelona, por Francisco Generas, año 1777.

(88) Ibid., p. 107.

(89) Ibid., p. 104.

(90) Fondo Familia Alegre, Carta de D. Pedro Pablo Gregori a D. Antonio Martínez y de Pons, 2-6-1778».

(91) Ibid.

(92) JUAN SEMPERE Y GUARINOS: Op. cit., pp. 104-105.

(93) MARCELO MIRAVETE DE MASERES: El Espudeo..., «Advertencia», s/n.

(94) Ibid.

(95) MARCELO MIRAVETE DE MASERES: Junta de Piedad..., p. 9.

(96) Ibid., pp. 6 y 7.

(97) Ibid., p. 24.

(98) Ibid., p. 19.

(99) Ibid., p. 20.

(100) Ibid., p. 17.

(101) Ibid., p. 33.

(102) ERWIN H. ACKERKNECHT, op. cit., p. 146.

(103) MARCELO MIRAVETE DE MASERES: Junta de Piedad..., p. 21.

(104) Ibid.

(105) Ibid., p. 22.

(106) Ibid., pp. 36-37.

(107) Ibid., p. 22.

(108) Ibid., p. 23. 
(109) Ibid., p. 25.

(110) Ibid.

(111) Ibid., p. 27

(112) Ibid., p. 28.

(113) Ibid., p. 30.

(114) MARCELO MIRAVETE DE MASERES: El Espudeo..., p. LXXXIII.

(115) Ibid., p. LXXXVI-LXXXVII.

(116) Ibid., p. LXXXVII.

(117) Ibid., p. CXXII.

(118) Ibid.

(119) Archivo Municipal de Orihuela, "Actas capitulares, 1793», Fols. 11r-12r.

(120) MARCELO MIRAVETE DE MASERES: El Espudeo..., p. XCVII. 